\title{
Echocardiography: golden method in the diagnosis of congenital heart anomalies
}

\section{Arbnore Batalli- Këpuska* \\ Ramush Bejiqi Arlind Batalli}

University Clinical Center of Kosovo, Pristina, Kosovo

RECEIVED:

April 1, 2015

ACCEPTED:

April 20, 2015

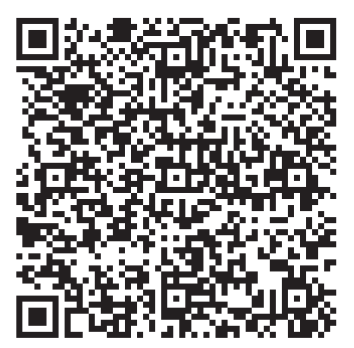

KEYWORDS: echocardiography, congenital abnormalities.

CITATION: Cardiol Croat. 2015;10(3-4):62. | DOI: http://dx.doi.org/10.15836/ccar.2015.62

*ADDRESS FOR CORRESPONDENCE: Arbnore Batalli-Këpuska, University Clinical Centre of Kosova, Rrethi i Spitalit, p.n., Prishtina, Kosova. Phone: +377-44-207-268. Email: drnorakep@hotmail.com

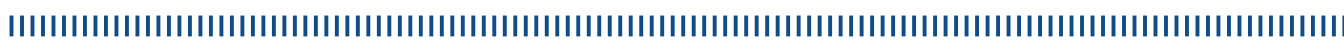

INTRODUCTION: Congenital heart abnormalities are fairly common anomaly, that are numbered in second place after urinary tract anomalies. Large problem presents complex heart abnormalities due to lack of cardiological center in our country. The aim was to present the congenital heart abnormalities in the period January-June 2013 at children aged 1-12 months

PATIENTS AND METHODS: All outstanding children with congenital anomalies have been hospitalized at the Pediatric Clinic at the Cardiology and Rheumatology Department. At children are taken routine laboratory tests (erythrocyte sedimentation rate, blood, urea, creatinine, glycaemia, urine) at all children has become conducted chest X-ray. Golden method in diagnosing the correct congenital heart abnormalities has been echocardiography.

RESULTS: Out of 22 children with congenital heart anomalies 4 children have been with tricuspid valve atresia, 3 children with Tetralogy of Fallot, 3 children with pulmonary artery atresia, 2 children with truncus arteriosus communis, 3 children with hyperplastic left heart syndrome, 6 children with transposition of large blood vessels and 1 child with total spill anomaly of pulmonary veins.

CONCLUSION: Although our country conducts accurate diagnosis of congenital heart anomalies, still due to lack of cardiological center mortality is high. 